\title{
EFFECT OF THE INTERFACE ON THE MECHANICAL PROPERTIES
}

\section{OF COMPOSITE MATERIALS}

$$
20674
$$

Lawrence J. Broutman*

Bhagwan Das Agarwal**

Presented at the Sixth International Congress of Rheology

$$
\text { Lyon; France }
$$

September $4-8,1972$
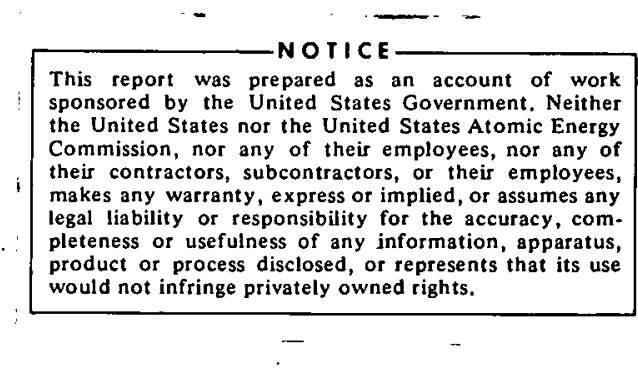

* Professor of Materials Engineering, Department of Metallurgical and Materials Engineering

* * Research Assistant, Department of Mechanics, Mechanical and Aerospace Engineering 


\section{DISCLAIMER}

This report was prepared as an account of work sponsored by an agency of the United States Government. Neither the United States Government nor any agency Thereof, nor any of their employees, makes any warranty, express or implied, or assumes any legal liability or responsibility for the accuracy, completeness, or usefulness of any information, apparatus, product, or process disclosed, or represents that its use would not infringe privately owned rights. Reference herein to any specific commercial product, process, or service by trade name, trademark, manufacturer, or otherwise does not necessarily constitute or imply its endorsement, recommendation, or favoring by the United States Government or any agency thereof. The views and opinions of authors expressed herein do not necessarily state or reflect those of the United States Government or any agency thereof. 


\section{DISCLAIMER}

Portions of this document may be illegible in electronic image products. Images are produced from the best available original document. 


\section{INTRODUCTION}

In previous papers $(1,2)$ we have analyzed the internal stresses in spherical particle composites for the cases where the particle is softer than the matrix $(1)$, as in rubber particle filled polymers, or for the case where the particle is harder than the matrix as in ceramic filled glasses ${ }^{(2)}$. Also, the analysis has been applied to porous composites such as foams in which case spherical voids simply replace the particles $^{(2)}$. A finite element analysis has been used for the calculation of internal stresses and for the prediction of elastic constants and strength of the composite with a suitable model geometry and proper boundary conditions. The results have been presented as a function of the volume fraction of particles or inter-particle spacing.

In this paper, results are presented for spherical particle composites in which the interfacial zone has elastic properties different from that of the particle or matrix. The influence of changing the interface properties on the internal stress distribution in the composite and on the predicted elastic constants will be discussed. Also discussed is the interface in an aligned discontinuous fiber composite and its effect on composite properties such as elastic constants, strength and toughness.

\section{SPHERICAL PARTICLE COMPOSITES}

1) Approximations and Boundary Conditions.

The present investigations were carried out using an analysis of axisymmetric solids. In the finite element approximation of axisymmetric solids, the continuous structure or medium is replaced by a system of axisymmetric elements interconnected at nodal circles. It was assumed that a spherical particle composite (assumed to possess symmetry) could be approximated by a unit cell (Fig. 1) which when rotated $360^{\circ}$ around axis $A D$ produces a hemisphere embedded within a cylinder. The interparticle spacing is equal to $2\left(r_{1}-r_{2}\right) ; r_{1}$ and $r_{2}$ are shown in Fig. 1 . The volume percent of filler particles or cavities (radius $=r_{2}$ ) can be altered and calculated from 
the ratio $r_{2} / r_{1}$ (note $A B=B C=C D=A D$ in Fig. 1). This axisymmetric representation of the composite only approximates its real packing and structure. These axisymmetric cells are not an actual repetitive unit but are related in their dimensions to the interparticle spacing.

The unit cell shown in Fig. 1 is subdivided into small elements as shown in Fig. 2 or Fig. 3. The finite element method permits calculation of the stresses in all the elements and the displacements at the nodal circles for any loading and boundary conditions. It is assumed that the composite is strained in the z-direction and that no tractions are applied in the r-direction. By symmetry, on the boundary $A B C D$ (Fig. 1) the shear stresses are:

$$
\tau_{r z}=\tau_{z r}=0
$$

The sides $A B$ and $B C$ remain parallel to their original positions after they are displaced due to strain in the $z$ direction, whereas the normal displacements of $A D$ and $D C$ are zero. Thus, $A B$ and $B C$ will undergo normal displacements, and the traction in the $r$ direction must be zero so that:

$$
\int_{B C} \sigma_{r} d z=0
$$

where the integral is replaced by a summation in the finite element method.

The following assumptions were made concerning the material:

1) Filler particles are spherical and of uniform size; packing of particles can be represented by an axisymmetric element (Fig. 1 ).

2) Both filler, matrix and interface materials obey elastic stress-strain relationships.

3) Perfect bonding exists at the interfaces (continuity of displacements at each interface).

The calculations were made on a large digital computer* by using a computer

* Univac 1108, Univac Div., Sperry Rand Corp., Philadelphia, Pa. 
program for the analysis of axisymmetric solids written by E. L. Wilson ${ }^{(3)}$. The boundary conditions were prescribed in the mixed mode i.e., the displacements were prescribed on some of the boundaries whereas tractions were prescribed on the others. The prescribed boundary displacements were selected to obtain the desired composite strains. The average composite stress was calculated from a knowledge of the stresses in the elements at the boundary of the unit cell. The composite sfresses and strains are used to calculate the composite modulus of elasticity and Poisson's ratio. The details of the procedure to satisfy the boundary conditions and to calculate composite stress, strain, modulus of elasticity and Poisson's ratio have been given in previous papers $(1,2)$.

2) Effect of a Weak Interface on Composite Properties.

In an actual composite material, the properties of the material at the interface may be different from those of the filler and matrix. Continuous displacements at the interface imply perfect bonding between the filler particles and the matrix. When perfect bonding does not exist between the filler and the matrix the behavior of the interface should be simulated by assigning different property values to the material at the interface. This is very easily accomplished using the axisymmetric finite element method. The shaded elements in Figs. 2 and 3 have been assumed to represent the finite thicknesses of the interface for filler contents of $3.04\left(r_{2} / r_{1}=0.357\right)$ and $24.30\left(r_{2} / r_{1}=0.714\right)$ percents respectively. The shaded elements account for 0.48 percent of the total volume in the former case and 3.02 percent in the latter case. The modulus of elasticity assigned to the elements at the interface was 1000 psi which is very small compared to that of the assumed glass matrix $\left(E-11.8 \times 10^{6} \mathrm{psi}\right)$ or the ceramic filler $\left(E=60.4 \times 10^{6} \mathrm{psi}\right)$. This represents the case of a very weak interface. The weak interface as described above completely changes the stress distribution around the interface. The stresses in the elements (in the matrix) adjacent to the 
interface have been plotted in Figs. 4 and 5. A zero value of radial stress around the interface indicates a free boundary. The curves for tangential stresses with the finite interface are very similar to the ones previously obtained for stresses around a cavity ${ }^{(2)}$. Due to very low modulus, the interface is not able to transfer much stress from the matrix to the hard inclusions and therefore this represents a case of filler particles completely debonded from the matrix. The hard inclusions with the soft interface carry very low stresses and hence do not contribute to the enhancement of the modulus of the composite. This is similar to what Stett and Fulrath ${ }^{(4)}$ have described as pseudoporosity which results in a weakening of the composite. The modulus of elasticity of the composite decreases with higher filler contents as indicated in Table. 1.

Table 1

Effect of Interface on Modulus of Elasticity of Composite

Volume Fraction

Filler

3.04

24.30

43.83
Composite Modulus (psi)

Without Interface

$12.3 \times 10^{6}$

$16.7 \times 10^{6}$

$22.4 \times 10^{6}$
With Soft Interface

$11.05 \times 10^{6}$

$6.97 \times 10^{6}$

$3.84 \times 10^{6}$

It is not unexpected that the modulus of the composite will decrease since less stress is transferred to the hard particles. Thus, as the volume percent of filler increases the difference in modulus increases as can be seen in Table 1.

\section{ELASTIC ANALYSIS OF THREE PHASE FIBROUS COMPOSITES}

a) Introduction

In the case of continuous fiber reinforcement, the effect of fiber ends, where the load is transferred by the matrix, is generally considered insignificant. The fiber 
stress is assumed to be constant over the whole length of the fibers. The principal purpose of the matrix is to bind the fibers together. The strength of the composite is then dependent upon the strength of the fibers. However, in studying the details of fracture of continuous fiber composites it has been found that individual fibers fail well before the entire composite fractures. Thus, in this case, the load transferred to the broken fibers by the matrix and the interfacial conditions may thus influence composite fracture particularly as the number of broken fibers increases.

In a discontinuous fiber-reinforced composite the properties of the composite are a function of fiber length and the attainment of high strength in the composite will depend upon efficient load transfer from the matrix to the fibers. Therefore, it is of considerable interest to understand how stress builds up in each individual fiber. A study of the length required for effective reinforcement and the factors influencing this length such as the properties of the material at the interface and the fiber end condition, should thus be helpful in guiding the development of composites of this type.

It is well known that in discontinuous fiber reinforced systems with all fiber axes parallel to the direction of loading, the mechanism of load transfer from matrix to the fiber is an interfacial shear stress. A number of analytical studies concerning this shear stress transfer have been carried out using simplified models. Fiber-matrix interaction has been studied for elastic matrices by Cox ${ }^{(5)}$, Dow ${ }^{(6)}$, and Rosen ${ }^{(7)}$. They give expressions for axial fiber stress and for the shear stress at the fiber matrix interface as a function of position along the fiber length. These expressions are quite similar to each other, although different assumptions were made in deriving them. Tyson and Davies ${ }^{(8)}$, and Schuster and Scala ${ }^{(9)}$ measured interfacial shear stress between a metal fiber and epoxy resin by using photoelastic techniques. Studies of Fujiwara $^{(10)}$ for resin-fiber load transfer in a single fiber-resin composite indicate that 
the stress distribution depends upon glass fiber finishes, especially under wet conditions. Carrara and McGarry ${ }^{(11)}$ studied the effect of fiber end geometry on the stresses near the end of an elastic fiber embedded in an elastic matrix. They found that the stresses depend strongly on the geometry of the fiber tip. More recently, MacLaughlin and Barker ${ }^{(12)}$ investigated the effect of modulus ratio on stress near a discontinuous fiber. They analyzed a two-dimensional plane stress composite configuration using Moire strain analysis and finite element analysis. In the study presented here the properties of the interface between fiber and matrix have been varied in order to determine the influence of the interface on certain properties of the composite.

\section{2) Representative Model.}

Unidirectional discontinuous fibers were assumed to be packed in a regular array as shown in Fig. 6. Although this does not represent an actual packing of the fibers in the composite, this idealization is necessary for an axisymmetric analysis.

It was assumed that the fibrous composite could be approximated by a cell (Fig. 7) which when rotated $360^{\circ}$ around axis $A D$ produces a cylinder embedded within a cylinder. The interfiber spacing is equal to $2\left(r_{1}-r_{2}\right)$ in both directions as shown in Fig. 7. The finite elements used for the case $\frac{r_{2}}{r_{1}}=0.67$, are shown in Fig. 8(A). Based on a cylinder within a cylinder, this corresponds to a fiber volume fraction equal to 42.4 percent. The fiber aspect ratio used (ratio of fiber length to fiber diameter, $1 / d$ ) is 10.375 . The elements adjacent to the fiber (shaded elements in Fig. 8 B) have been assumed to represent the finite thickness of the interface. The property values (the modulus of elasticity and Poisson's ratio) assigned to these elements are changed to simulate a change in the interface conditions. A high modulus of elasticity of the interface represents a strong interface capable of transferring more load whereas a low modulus represents a weak interface. The 
shaded elements account for 7.76 percent of the total volume. In some cases the thickness of the interface was reduced by a half to study the effect of this change. The elements adjacent to the fiber end may be assigned property values different from those for the interface. This enables one to study the effect of fiber end condition on the stress distribution. For example, a very low modulus of elasticity for these elements may be assumed to represent a debonded end because a negligible load will be transferred through the fiber end.

\section{3) Boundary Conditions and Component Properties.}

Stresses in three dimensions were calculated in all the elements shown in Fig. 8 for various interface conditions. As in the case of the particulate composites, the stress-strain relations of the matrix and the fibers were assumed elastic. The stress-strain relations for the materials at the interface and the fiber end were also assumed elastic. It was also assumed that the composite is loaded by a force in the $z$ direction and that no tractions are applied in the $r$ direction. These assumptions lead to boundary conditions identical to those for the particulate composite described previously. Therefore, the procedure to satisfy these boundary conditions and the subsequent calculation of the composite modulus and Poisson's ratio are also identical.

The following component properties, typical of a glass reinforced plastic, were assumed:

$$
\text { Matrix } \quad \begin{aligned}
E & =0.4 \times 10^{6} \cdot \mathrm{psi} \\
& \nu=0.35 \\
\text { Fibers } \quad E & =11.8 \times 10^{6} \mathrm{psi} \\
\quad \nu & =0.197
\end{aligned}
$$

Properties of the interface were varied over a wide range. Investigations were carried out using eleven different combinations of property values as shown in Table 2. 
Table 2. Properties of the Interface

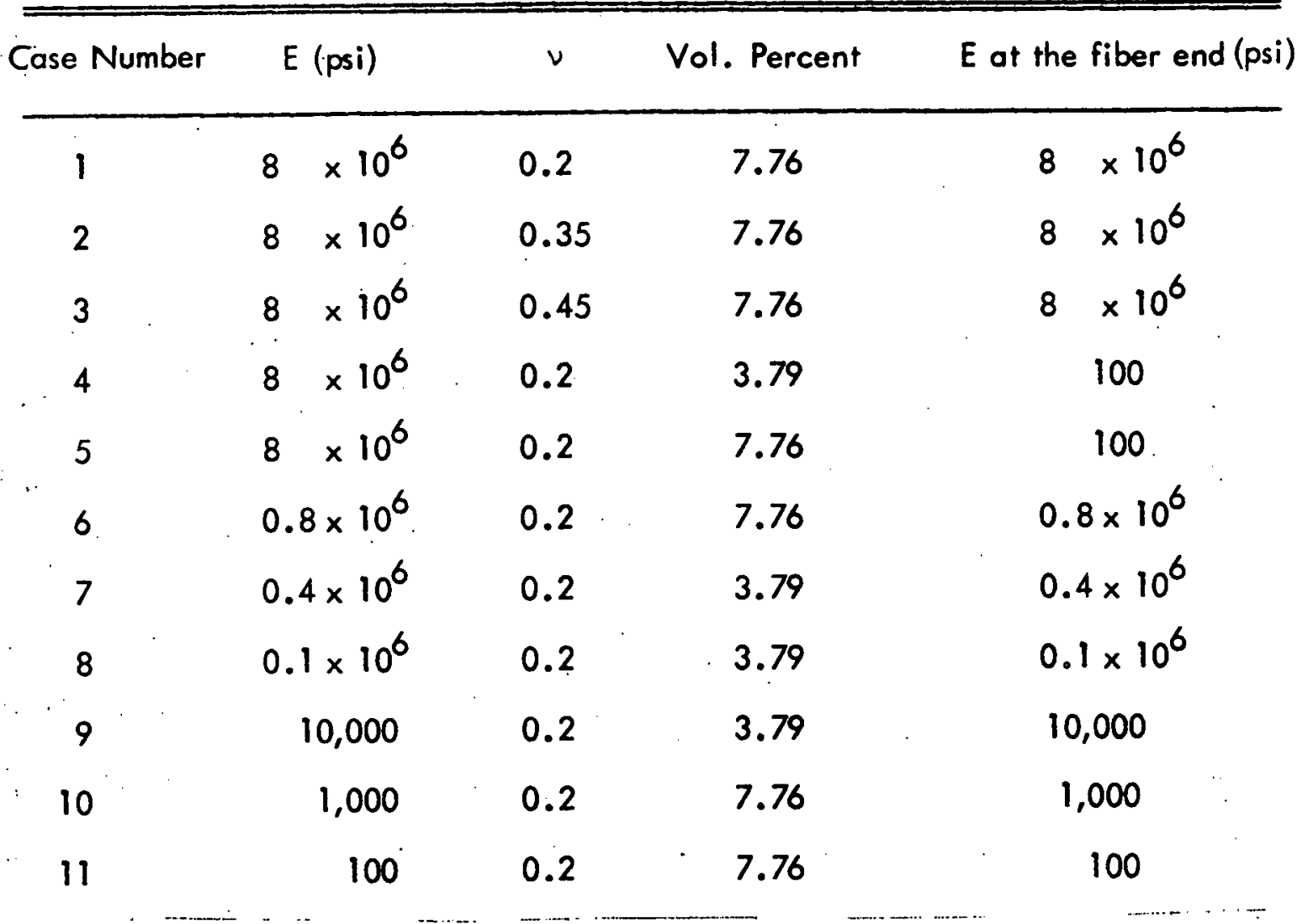

Modulus of elasticity of the interface has been varied from a very high value of $8 \times 10^{6}$ psi which is close to that of the fibers to a very low value of only 100 psi which may be considered to represent debonding of the fibers from the matrix. The first three cases have been selected to study the effect of varying Poisson's ratio of the interface. Also, note that the modulus of elasticity of the elements adjacent to the fiber end is the same as that of the interface for all cases except for 4 and 5 . For these two cases it has a very low value (100 psi) compared to that of the interface. This represents a case of strong interface with debonded fiber end. The only difference in the case 4 and the case 5 is the thickness of the interface which would change the volume percent of the interface.

A) Effect of Interface on Internal Stresses.

The stress distributions for three phase composites were obtained for all 
cases indicated in Table 2. In the first three cases, the Poisson's ratio of the interface was assigned three different values of $0.2,0.35$ and 0.45 while keeping all other properties unchanged. The stresses obtained in the three cases were almost identical to each other and hence they are not plotted separately. These stresses have been shown along with the other stress distributions for different interface elastic moduli.

Distributions of fiber axial stress along the length are shown in Fig. 9 for interface moduli varying from $8 \times 10^{6} \mathrm{psi}$ to $100 \mathrm{psi}$. When the interface modulus is near the matrix modulus or higher, the fiber axial stress attains a maximum value within two fiber diameters from the fiber end. The stress distributions for the three cases of interface moduli $\left(E=0.1 \times 10^{6}, 0.8 \times 10^{6}\right.$ and $\left.8 \times 10^{6}\right)$ are very similar to each other. As the interface modulus decreases to 10,000 psi, the fiber axial stress attains its maximum value in about four fiber diameter from the fiber end. But as the interface modulus further decreases to 1,000 psi or 100 psi, the fiber axial stress does not reach a constant value with the present fiber length of ten fiber diameters. Due to the low interface modulus, the interface does not transfer load from matrix to the fiber efficiently. In fact the modulus of 100 psi is so low that it represents the case of complete debonding of the fiber from the matrix as will be shown later.

Interfacial shear stress distributions for all the above cases, except for an interface modulus of $0.8 \times 10^{6}$ psi, have been shown in Fig. 10. The stress distribution for the interface modulus of $0.8 \times 10^{6} \mathrm{psi}$ is very close to the one for the interface modulus of $0.1 \times 10^{6}$ psi. The stress distributions in Fig. 9 are related to those in Fig. 10 because fiber stress build up is related to the shear stress at the interface as follows:

$$
\sigma_{f}=\sigma_{0}+\frac{2}{r} \int_{0}^{Z} \tau d Z
$$

where $r$ is the fiber radius, $\sigma_{o}$ is the stress at the fiber end, $\sigma_{f}$ is the stress in the 
fiber at any distance $Z$ from the fiber end, and the exact form of $\tau$ will depend upon relative properties of the fiber, interface and the matrix. The shear stresses at the fiber end for interface moduli of $0.1 \times 10^{6}$ and $8 \times 10^{6}$ psi are high and they drop down to zero in about two fiber diameters. Due to the high interfacial shear stress, the fiber axial stress increases rapidly and reaches a constant value as the shear stress drops to zero. For the interface modulus of 10,000 psi the shear stress does not drop to zero as quickly as in the previous cases and thus leads to a higher maximum stress in the fiber. Normalized shear stress at the fiber end for an interface modulus of 1000 psi is less than half of those in the previous cases. However, this does not decrease very fast away from the fiber end and hence the axial stress in the fiber builds up to about twice the stress on the composite. It may be expected that in this case the fiber stress could reach a constant value if the fiber was long enough. Interfacial shear stress in the case of an interface modulus of 100 psi is very small and therefore very little load transfer is possible from the matrix to the fiber.

Fiber axial stress at the end has been plotted as a function of log of interface modulus in Fig. 11. This stress gives an idea of the load transfer through the fiber end. At very low interface modulus the stress at the fiber end is very small indicating that no significant load transfer takes place through the fiber end. The stress at the fiber end increases with the increase of interface modulus. When the interface modulus is close to or higher than the matrix modulus, the fiber end stress is quite high indicating substantial load transfer through the end. As the interface modulus varies from $10^{5}$ psi to $8 \times 10^{6}$ psi there is not much change in the fiber end stress. Distribution of matrix axial stresses along the fiber length are shown in Fig. 12 for the interface moduli of 100,1,000,10,000 and $10^{5}$ psi. In all the cases the stresses increase sharply near the fiber end. They also show disconfinuities in the stresses upon passing the fiber end because of the physical discontinuity at this 
point. In the cases of interface moduli of $10^{4}$ and $10^{5}$ psi, the stresses away from the fiber end drop to a very low value indicating that most of the load has been transferred to the fibers. However, a low modulus of the interface (100 or 1,000 psi) does not help in the transfer of load from matrix to the fibers and therefore the axial stresses in the matrix away from the fiber end are considerably higher than the applied composite stress in these cases.

Radial stresses in the matrix have been plotted along the fiber length in Fig. 13 for interface moduli of 100, 1,000 and 10,000 psi. The stresses increase sharply near the fiber end. The stresses away from the fiber end are compressive when the interface moduli equal 1,000 and 10,000 psi. For the interface modulus of 100 psi, the radial stresses in the matrix are zero. It has also been shown that the axial stresses in the matrix adjacent to the fiber end are nearly zero for the interface modulus of 100 psi. The small magnitude of the stresses may be attributed to the size of the finite elements. Thus the normal stresses in the matrix adjacent to the fiber are zero indicating a free boundary. Therefore this represents a case of complete debonding of fibers from the matrix. This effect is the same as obtained in the case of particulate composites. Composite modulus has been plotted as a function of log interface modulus in Fig. 14. At very low interface modulus the fibers do not contribute to the stiffness of the composite. As explained earlier, this is due to the fact that the soft interface does not permit any load transfer from the matrix to the fiber. Therefore, the composite behaves as if these were voids of the size of the fiber and the interface. As the interface modulus increases, the load transfer takes place from the matrix to the fiber and consequently the composite modulus increases as shown in Fig. 14. The Halpin and Tsai equation ${ }^{(13)}$ may also be used to calculate the modulus of the two phase composite with discontinuous fiber reinforcement. For the modulus in the longitudinal direction, the equation can be written as: 


$$
\frac{E_{L}}{E_{m}}=\frac{1+\frac{2 \ell}{d} \cdot V_{f} \cdot \eta_{L}}{1-V_{f} \cdot \eta_{L}}
$$

where

$$
\eta_{L}=\frac{\left(E_{f} / E_{m}\right)-1}{\left(E_{f} / E_{m}\right)+2 \ell / d}
$$

and $E_{m^{\prime}} E_{f}$ and $E_{L}$ are the matrix, fiber and the composite moduli respectively. For the present case $\frac{E_{f}}{E_{m}}=\frac{11.8}{0.4}, \frac{\ell}{d}=10.375, V_{f}=0.424$ and $E_{m}=0.4 \times 10^{6}$ psi thus

$$
E_{L}=3.15 \times 10^{6} \mathrm{psi}
$$

This value of the composite modulus compares favorably with the value of $3.58 \times 10^{6}$ psi obtained for the two phase composite by the finite element method.

The onset of failure may be predicted from the knowledge of the stress distributions in the composite. Tothis end, distortion energy given as follows:

$$
U=1 / 2\left[\left(\sigma_{1}-\sigma_{2}\right)^{2}+\left(\sigma_{2}-\sigma_{3}\right)^{2}+\left(\sigma_{3}-\sigma_{1}\right)^{2}\right]
$$

(where $\sigma_{1}, \sigma_{2}$ and $\sigma_{3}$ are principal stresses) was calculated for all the elements (Fig. 8) for different interface moduli (normalized stresses were used for this calculation). The maximum value of distortion energy in any element of the matrix has been plotted as a function of interface modulus in Fig. 15. The maximum distortion energy always occurs in an element near the fiber end. The strength of the composite based on a von Mises failure criterion (i.e., the initiation of composite failure occurs as soon as the distortion energy in any element of the matrix reaches a limiting value) is shown qualitatively in Fig. 16. The actual strength values will depend upon the matrix strength. For very low interface modulus the strength of the composite is low due to high stress concentrations at the discontinuity. Strength of the composite increases as the interface modulus increases. But as the interface modulus changes from $10^{4} \mathrm{psi}$ to $8 \times 10^{6} \mathrm{psi}$, the composite strength remains almost constant. However, Fig. 14 
shows a significant change in the composite modulus over this range of interface modulus. Thus, the ultimate elongation of the composite can be controlled without affecting the failure stress by suitably controlling the interface modulus (using a surface treatment on the fibers during manufacturing). This also shows that a good combination of tensile strength and toughness (or the impact strength) may be obtained by suitably selecting the interface properties.

\section{CONCLUSIONS}

The influence of the interface on the internal stresses, composite modulus of elasticity and strength has been investigated. The interface has been altered by changing the modulus of a layer between the matrix and spherical particle or fibers. In the case of spherical particle composites it has been shown how a soft interface can reduce the composite stiffness as well as alter the internal stresses in the composite. The effect of altering the interface stiffness in an aligned short fiber composite can greatly effect the stress concentrations near a fiber end as well as the maximum stress transferred into the fiber. It has also been shown that the composite strength reaches a maximum and does not further increase when the interface modulus reaches a value of $10^{4}$ psi. However, the composite modulus continues to increase so that the composite elongation will begin to decrease (since all phases have been assumed to be elastic) when the interface modulus exceeds $10^{4}$ psi. Thus the strain energy absorbed by the composite can be maximized by controlling the interface modulus.

\section{ACKNOWLEDGEMENTS}

This research has been supported by the U.S. Atomic Energy Commission under Contract No. AT(11-1)-1794 and this support is gratefully acknowledged.

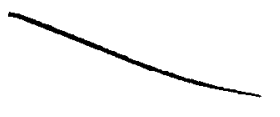




\section{BIBLIOGRAPHY}

1. Broutman, L. J. and Panizza, G., "Micromechanics Studies of Rubber Reinforced Glassy Polymers", Int. J. Poly. Mat., Vol. 1, 95-109, 1971.

2. Agarwal, B. D., Panizza, G.A., Broutman, L. J. "Micromechanics Analysis of Porous and Filled Ceramic Composites", J. of Am. Ceram. Soc., 54, 620-624 (1971).

3. Wilson, E.L., Structural Engineering Laboratory Report 63-1, University of California, Berkeley, Calif., June 1963.

4. Stett, M.A. and Fulrath, R.M., "Mechanical Properties and Fracture Behavior of Chemically Bonded Composites", J. Am. Ceram. Soc., 53 (1) 5-13, 1970.

5. Cox, H.L., "The Elasticity and Strength of Paper and Other Fibrous Materials", British J. Appl. Phys., Vol. 3, 72, 1952.

6. Dow, N.F., "Study of Stress Near a Discontinuity in a Filament Reinforced Composite Material", G.E.C., Missile and Space Division Report No. R63SD61, 1963.

7. Rosen, B.W., "Mechanics of Fiber Strengthening", Fiber Composite Materials, Chapter 3, ASM Publication for Seminar of ASM, October 1960.

8. Tyson, W.R. and Davies, G.J., "A Photoelastic Study of the Shear Stresses Associated with the Transfer of Stress During Fiber Reinforcement", British J. Appl. Phys., Vol. 16, 199, 1965.

9. Schuster, D.M. and Scala, E., "The Mechanical Interaction of Saphire Whiskers with a Birefringent Matrix", Trans. Met. Soc. of AIME, Vol. 230, p. 1635, Dec. 1964.

10. Fuiiwara, M., "Resin-Fiber Load Transfer in Fiber-Reinforced Plastics", MIT Research Report R67-8, February 1967.

11. Carrara, A.S. and McGarry, "Matrix and Interface Stresses in a Discontinuous Fiber Composite Model", J. Comp. Mat., 2(2), 222-243, April 1968.

12. MacLaughlin, T.F. and Barker, R.M., "Effect of Modulus Ratio on Stress Near a Discontinuous Fiber", Experimental Mechanics, 12(4), 178-183, April 1972.

13. Ashton, J.E., Halpin J.C., and Petit, P.H., Primer on Composite Materials: Analysis, Technomic Publishing Co., Inc., Stanford, Conn. 1969. 
VII. LIST OF FIGURES

Fig. 1. Unit Cell for Axisymmetric Representation of Sphere-Filled Composite

Fig. 2 Shaded Elements Represent Finite Thickness of the Interface for $r_{2} / r_{1}=0.357$.

Fig. 3 Shaded Elements Represent Finite Thickness of the Interface for $r_{2} / r_{1}=0.714$.

Fig. 4 Comparison of Matrix Stresses With and Without a Weak Interface in a Composite $\left(r_{2} / r_{j}=0.357\right)$.

Fig. 5 Comparison of Matrix Stresses With and Without a Weak Interface in a Composite $\left(r_{2} / r_{1}=0.714\right)$.

Fig. 6 Symmetrical Packing of Discontinuous Fibers in a Composite.

Fig. 7 Cell for Axisymmetric Representation of Fibrous Composite.

Fig. 8 (a) Finite Element Grid for $r_{2} / r_{1}=0.67$, and (b) Finite Thickness of the Interface Represented by Shaded Elements.

Fig. 9 Normalized Fiber Axial Stresses Along Fiber Axis in a Three-Phase. Composite.

Fig. 10 Normalized Interfacial Shear Stresses Along Fiber Axis in a ThreePhase Composite.

Fig. 11 Normalized Axial Stress at the Fiber End as a Function of Interface Modulus.

Fig. 12 Normalized Axial Stresses Along Fiber Axis in a Three-Phase Composite

Fig. 13 Normalized Matrix Radial Stress Along Fiber Axis in a Three-Phase Composite.

Fig. 14 Composite Modulus as a Function of Interface Modulus.

Fig. 15 Maximum Distortion Energy as a Function of Interface Modulus.

Fig. 16 Composite Strength as a Function of Interface Modulus (Qualitative Representation). 


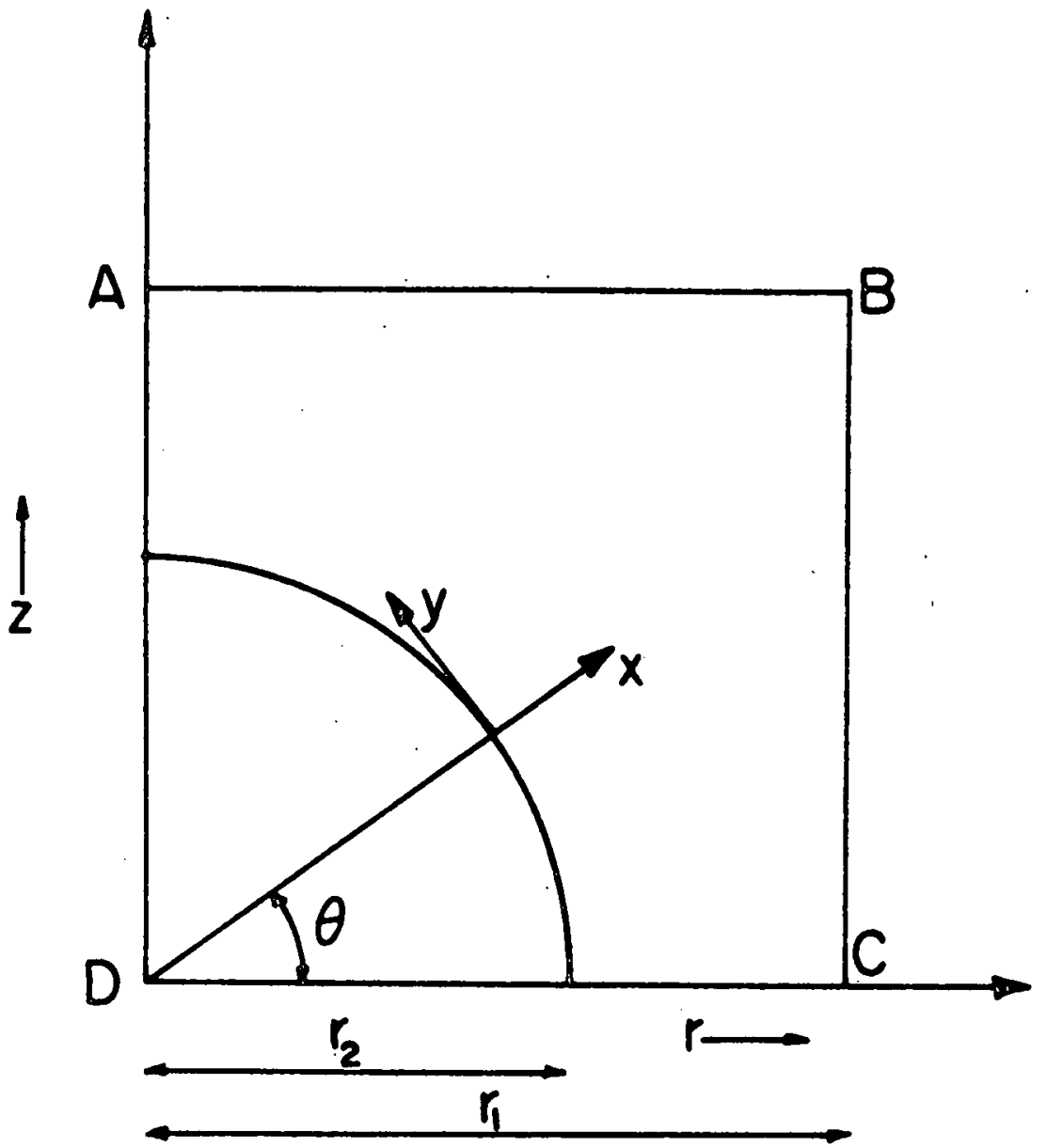

Fig. 1. Unit Cell for Axisymmetric Representation of Sphere-filled Composite 


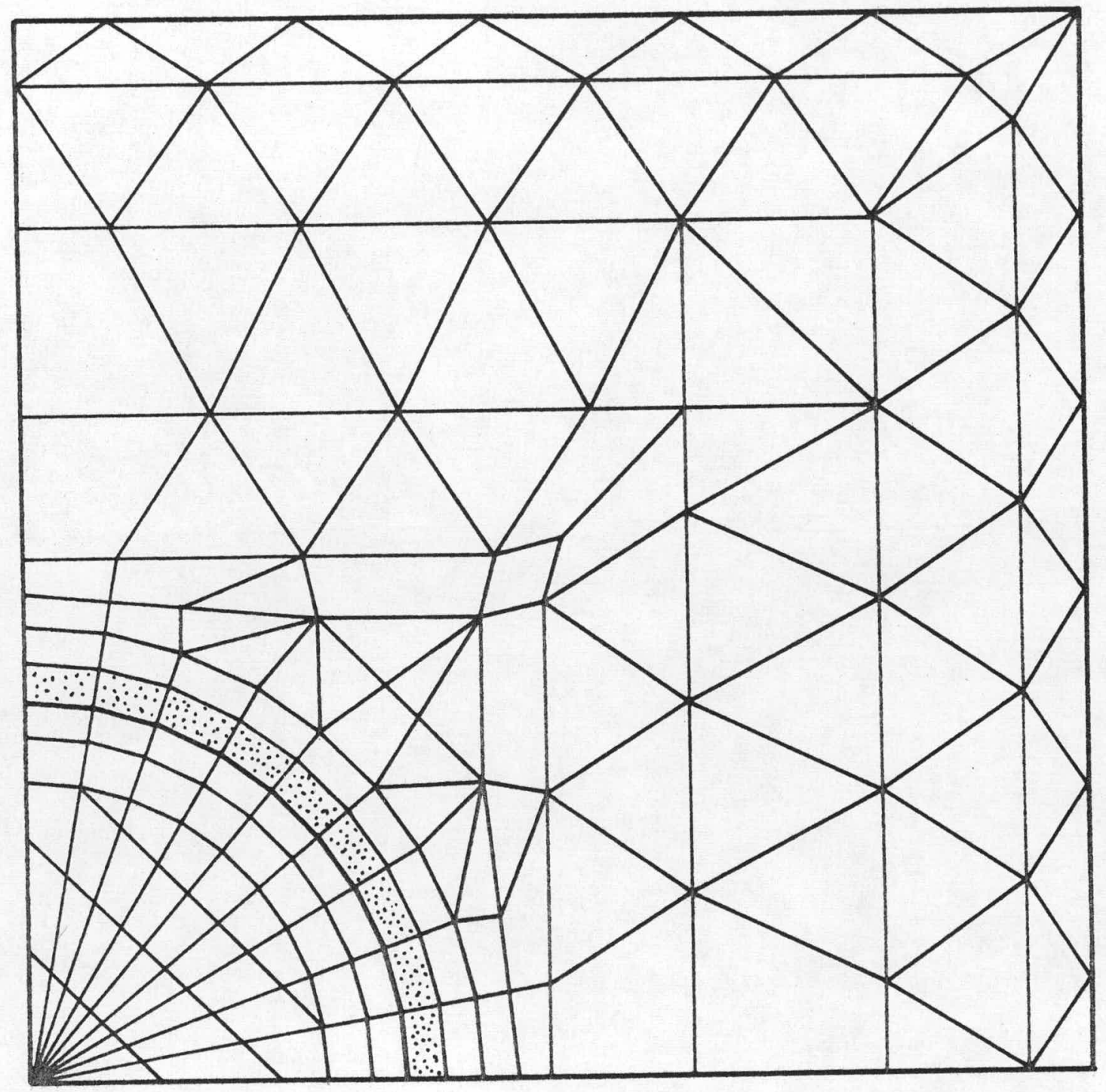

Fig. 2. Shaded Elements Represent Finite Thickness of the Interface for $r_{2} / r_{1}=0.357$ 


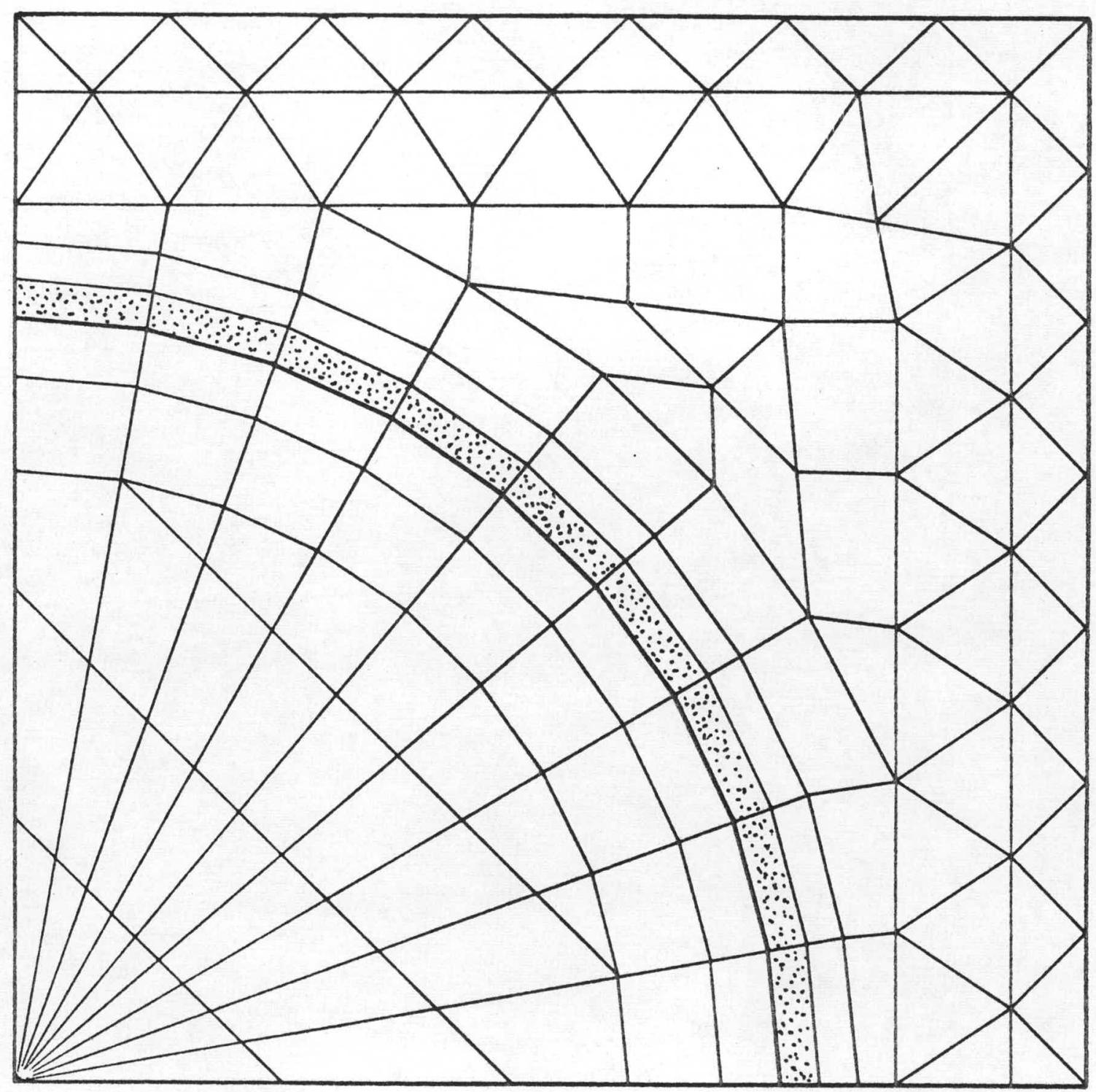

Fig. 3. Shaded Elements Represent Finite Thickness of the Interface for $r_{2} / r_{1}=0.714$ 


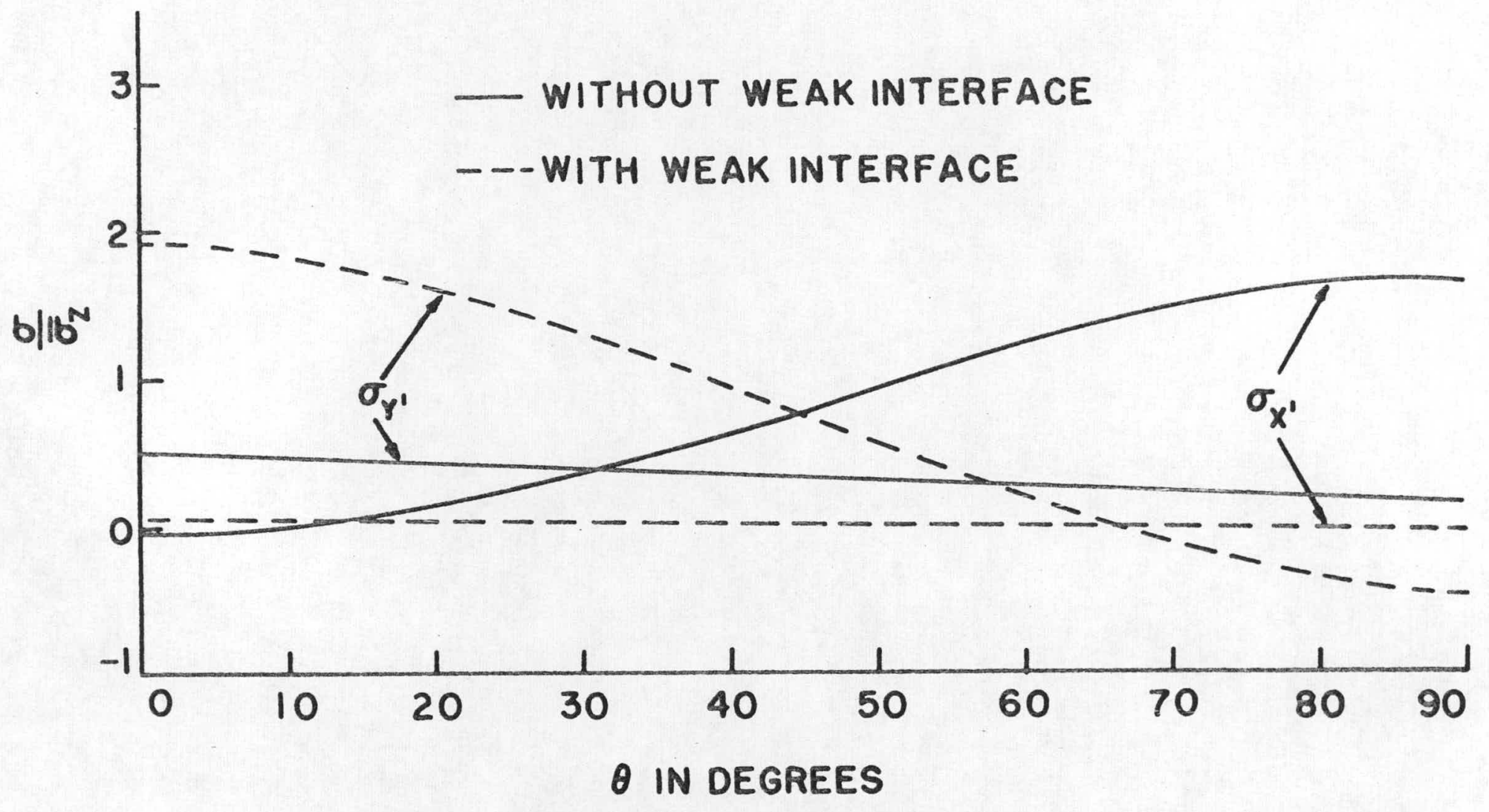

Fig. 4. Comparison of Matrix Stresses With and Without a Weak Interface in a Composite $\left(r_{2} / r_{1}=0.357\right)$ 


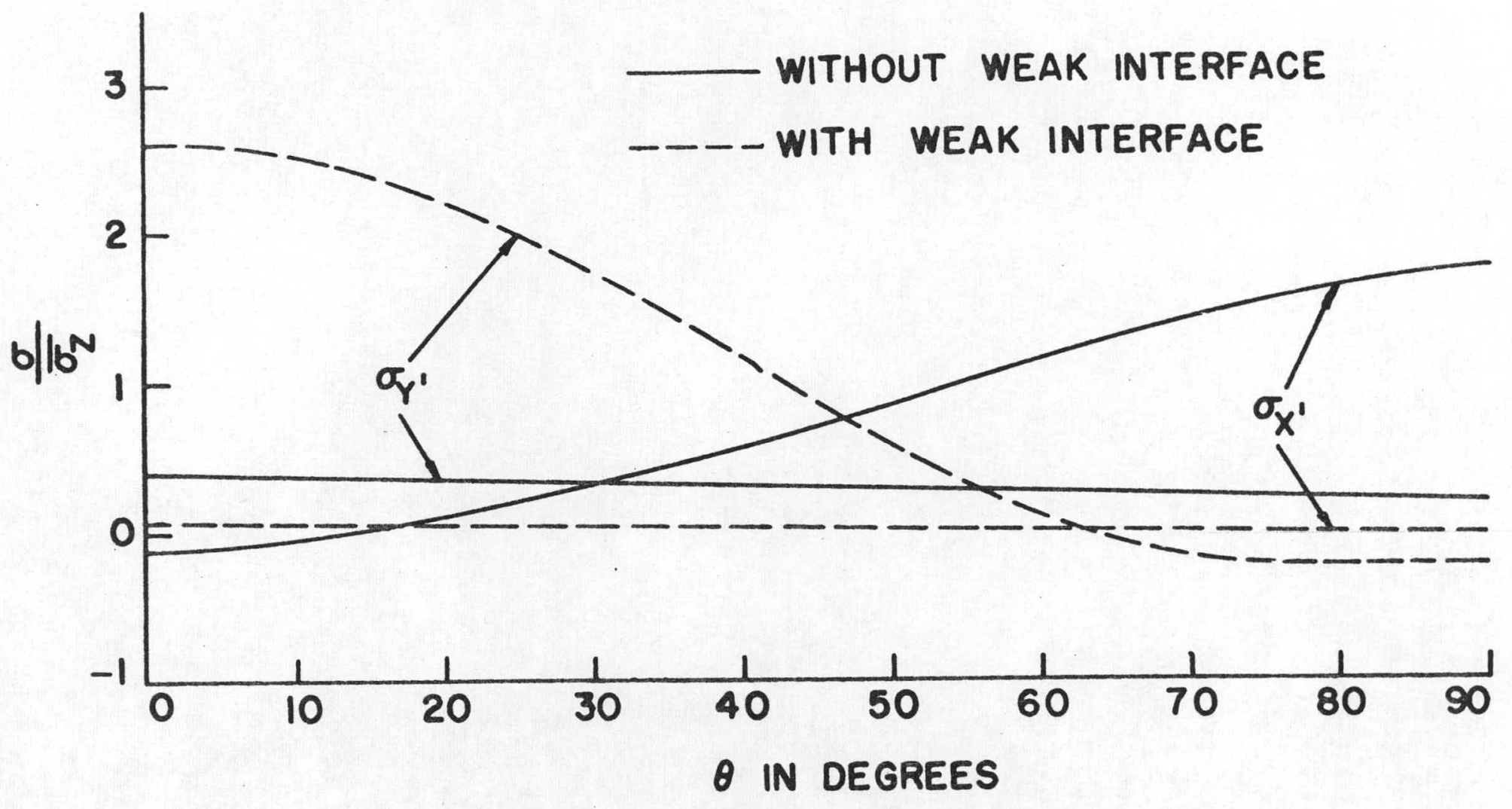

Fig. 5. Comparison of Matrix Stresses With and Without a Weak Interface in a Composite $\left(r_{2} / r_{1}=0.714\right)$ 


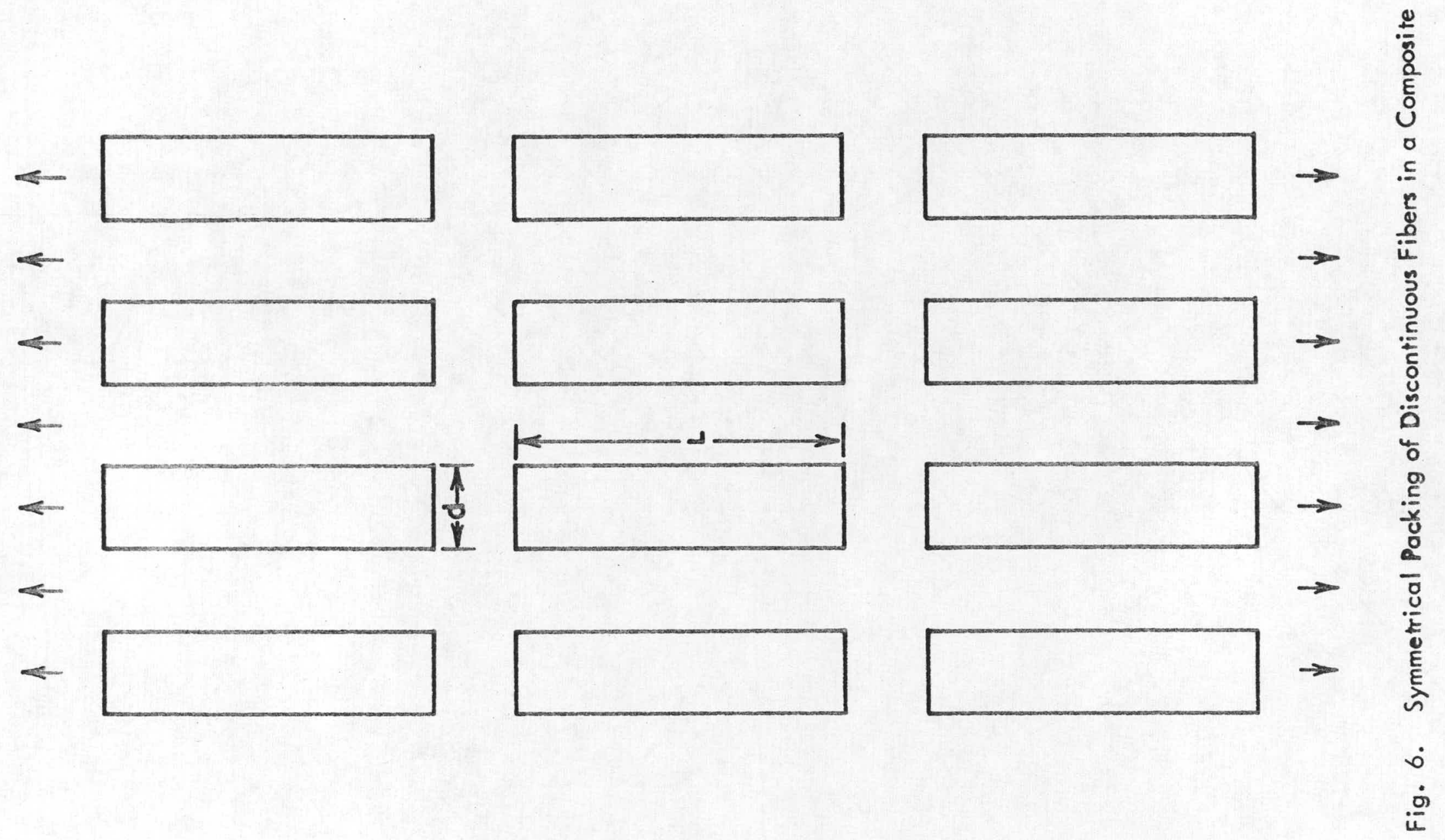




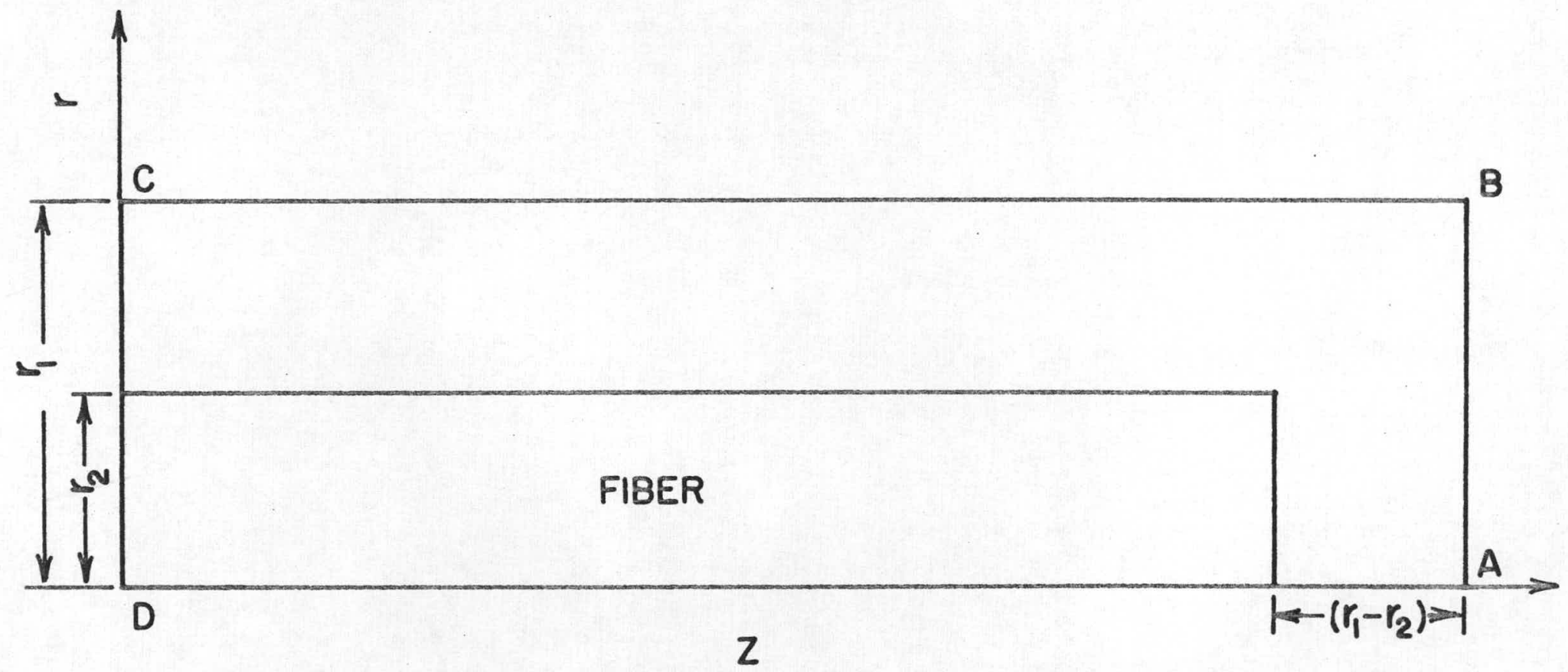

Fig. 7. Cell for Axisymmetric Representation of Fibrous Composite 


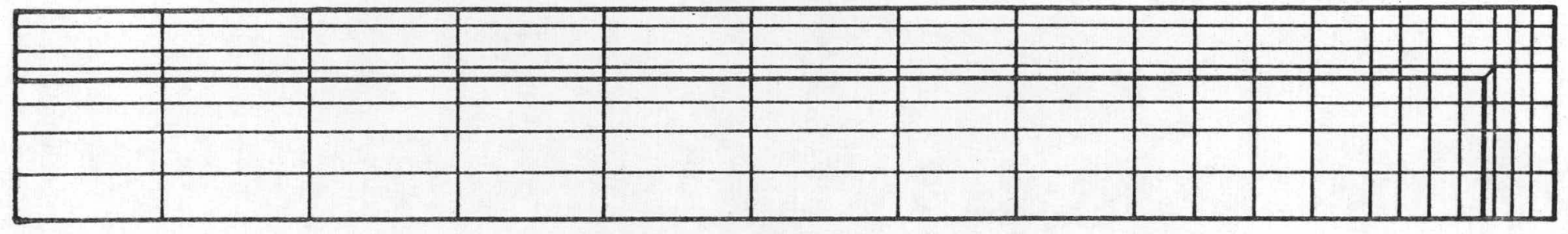

(A)

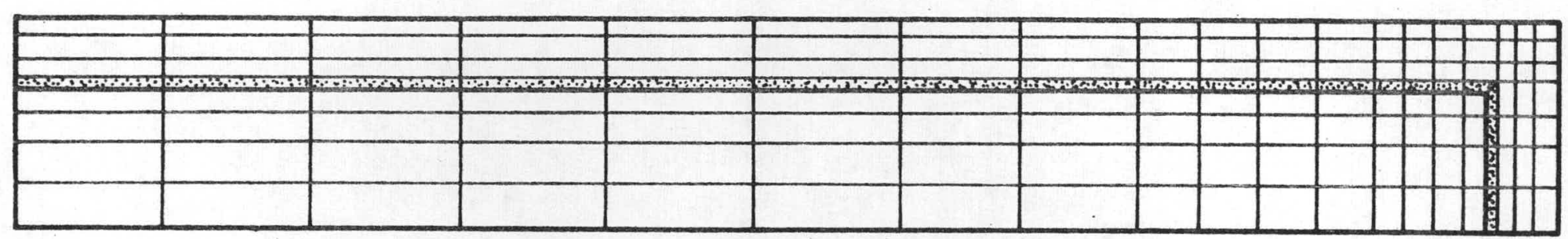

(B)

Fig. 8. (A) Finite Element Grid for $r_{2} / r_{1}=0.67$, and (B) Finite Thickness of the Interface Represented by Shaded Elements 


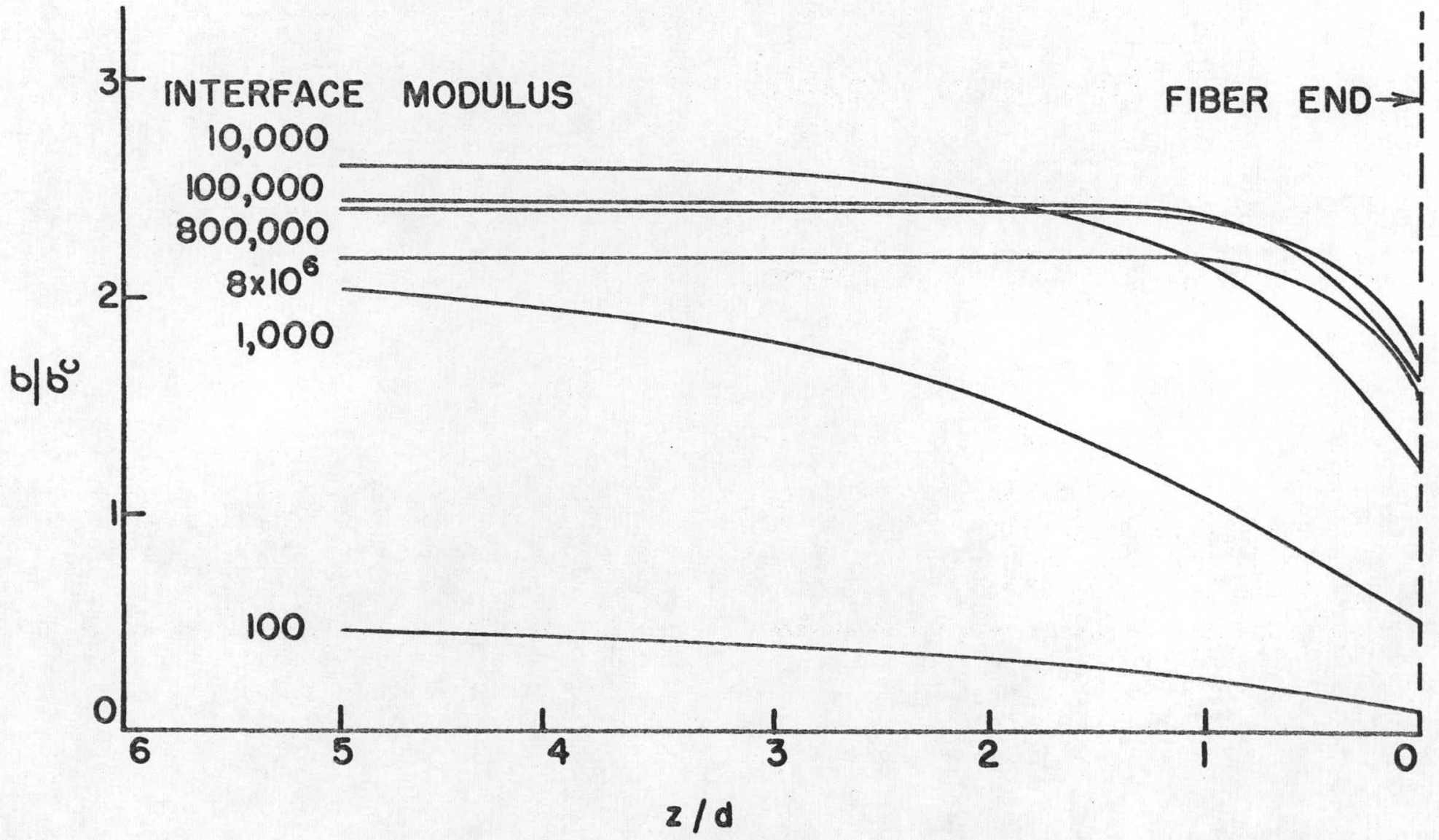

Fig. 9. Normalized Fiber Axial Stresses Along Fiber Axis in a Three-Phase Composite 


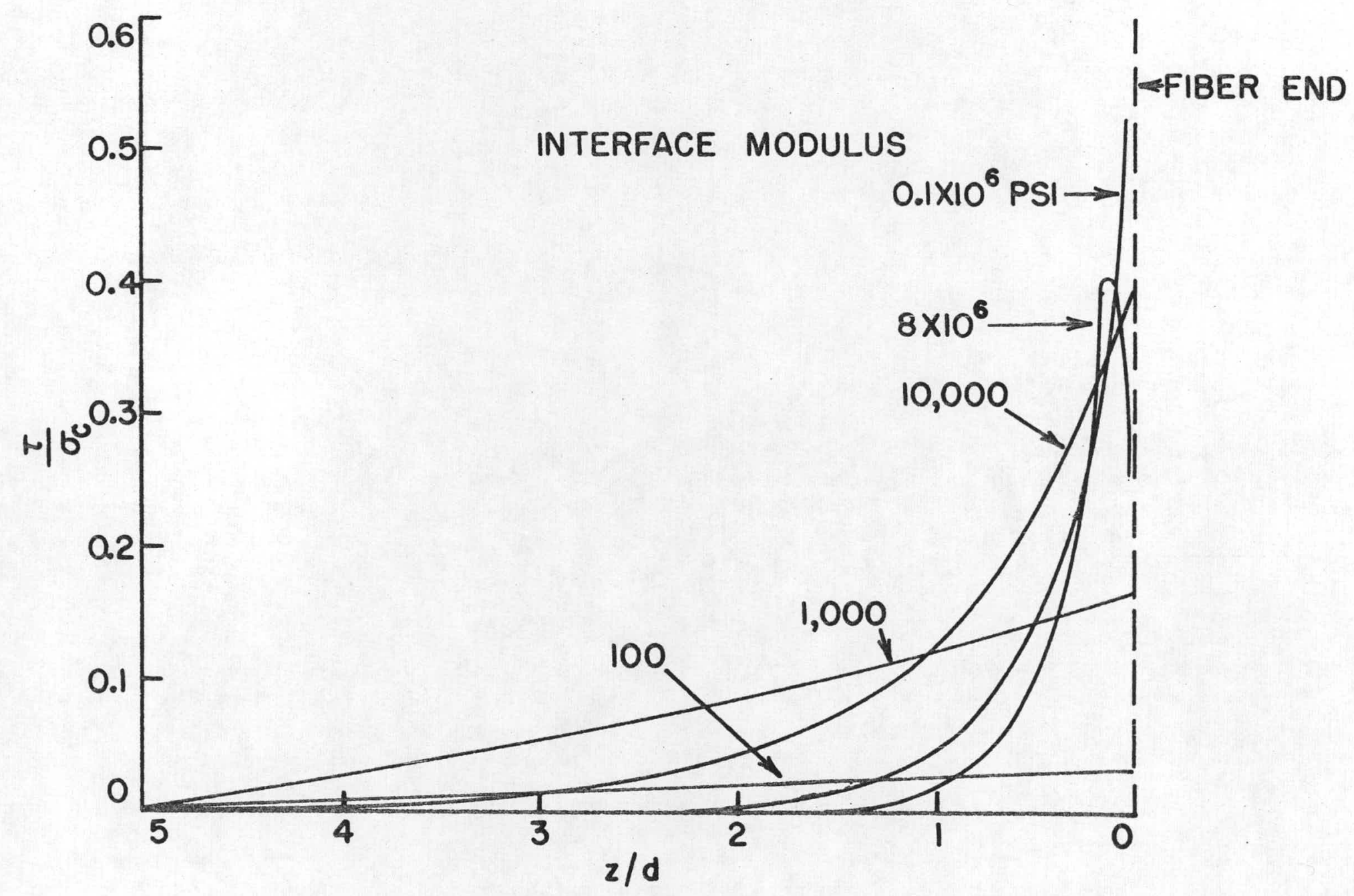

Fig. 10. Normalized Interfacial Shear Stresses Along Fiber Axis in a Three-Phase Composite 


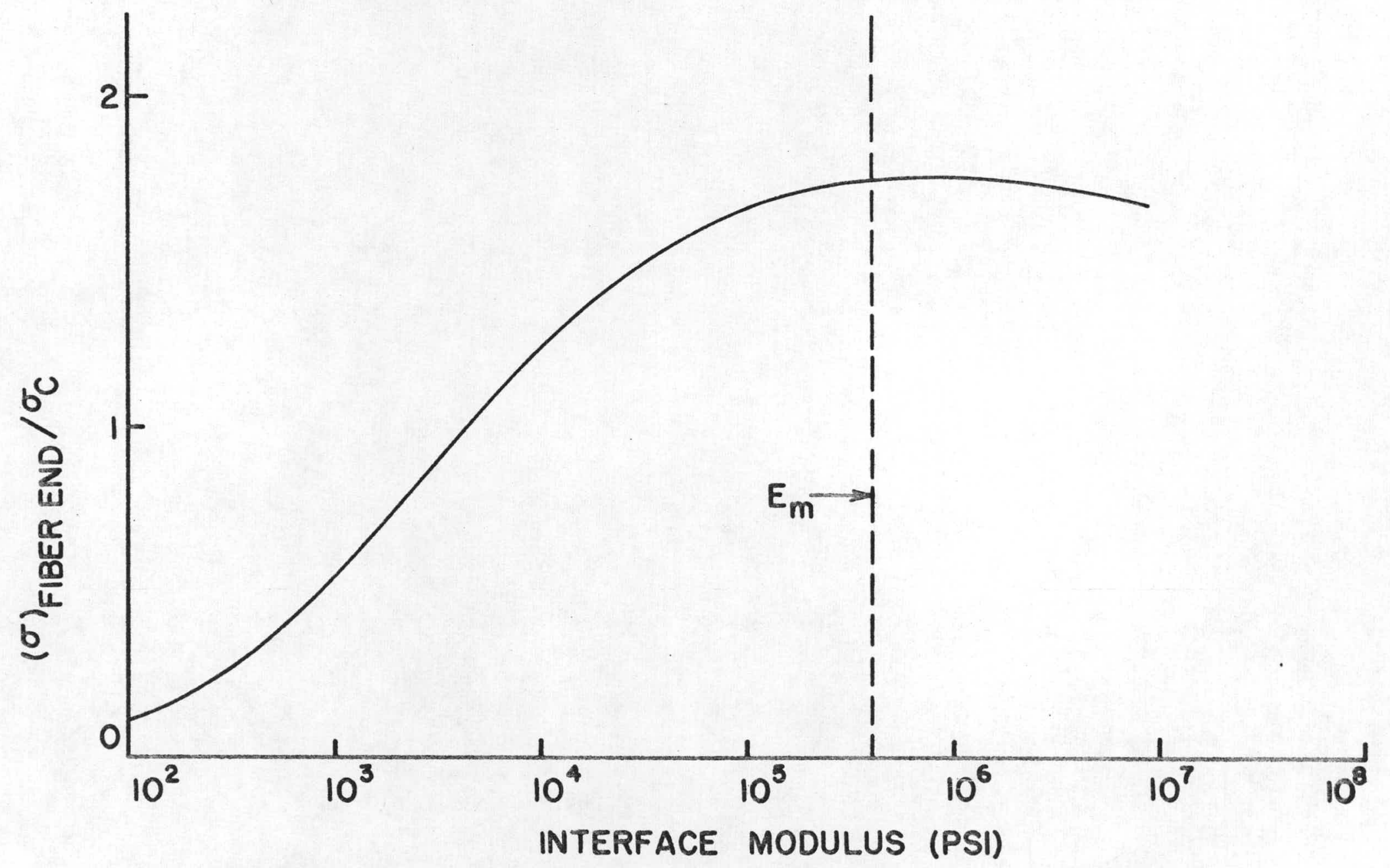

Fig. 11. Normalized Axial Stress at the Fiber End as a Function of Interface Modulus 


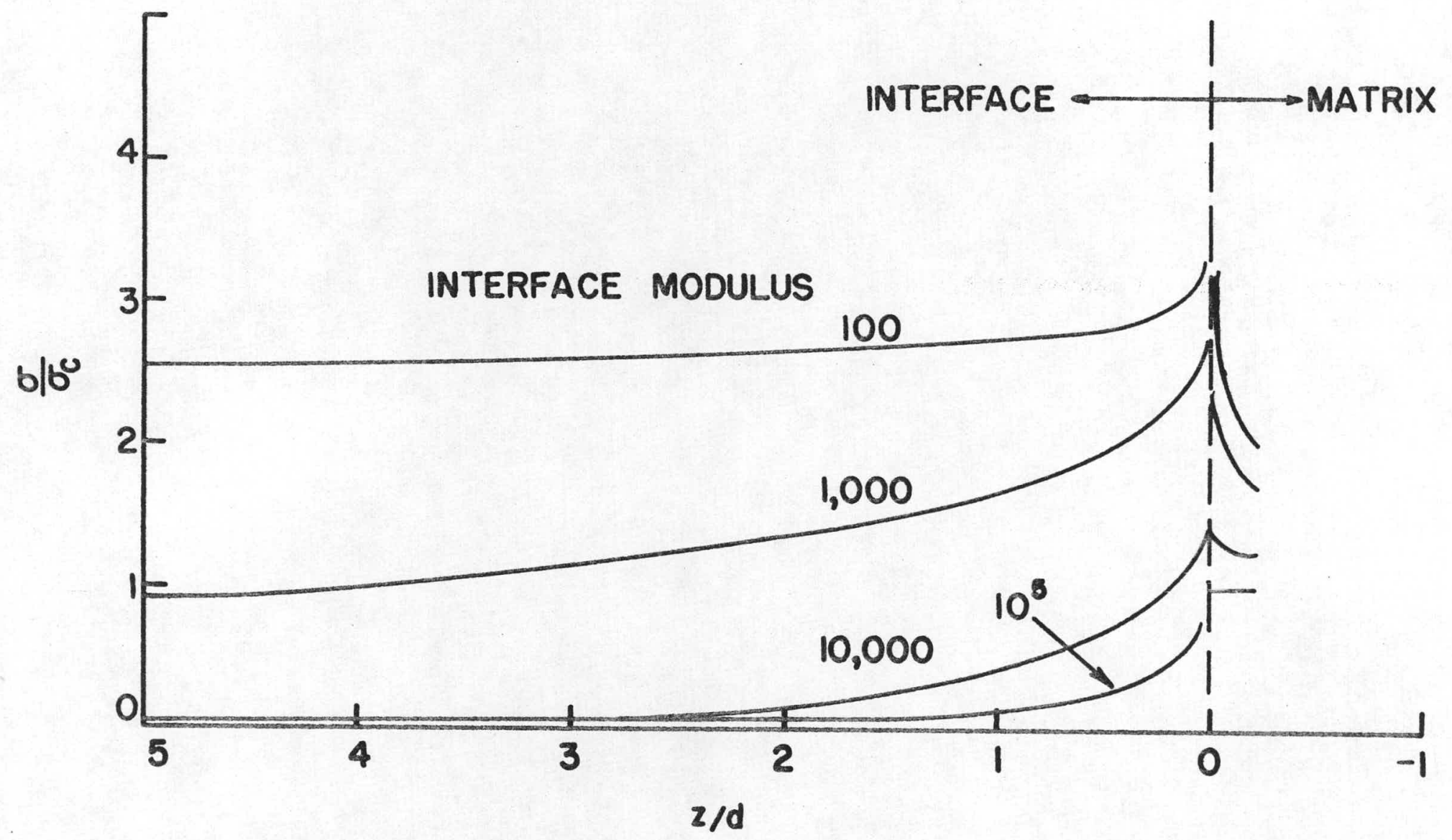

Fig. 12. Normalized Axial Stresses Along Fiber Axis in a Three-Phase Composite 


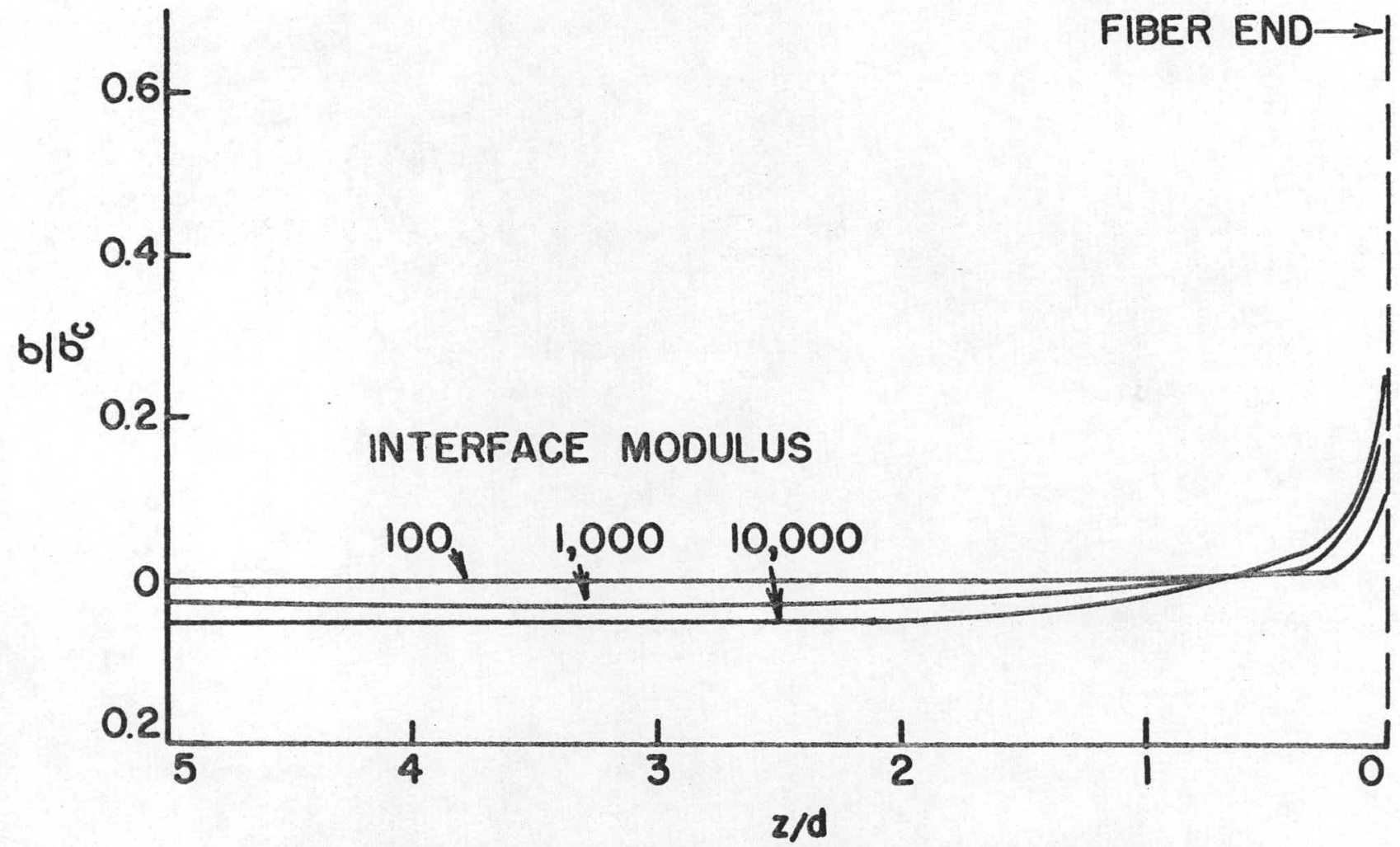

Fig. 13. Normalized Matrix Radial Stress Along Fiber Axis in a Three-Phase Composite 


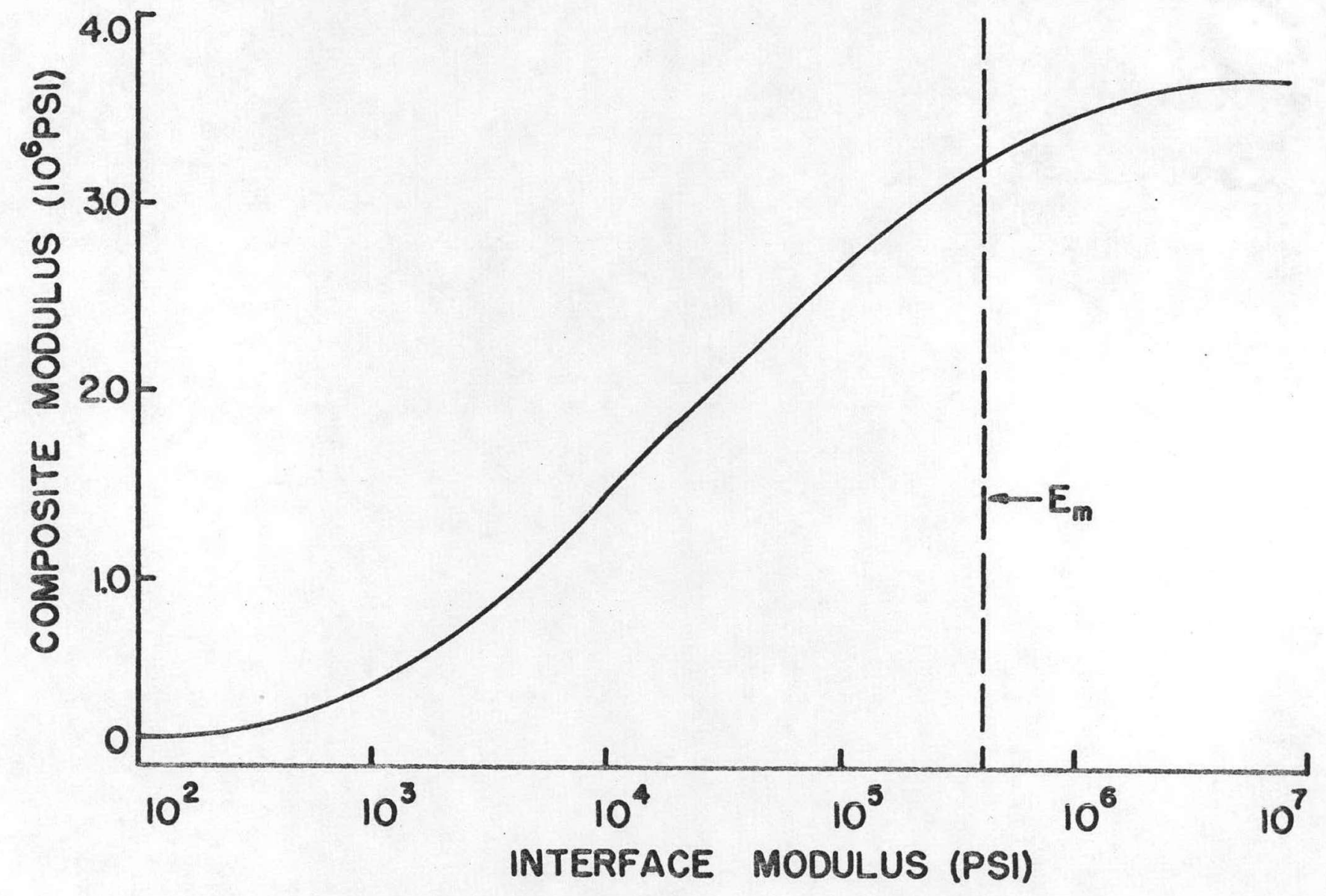

Fig. 14. Composite Modulus as a Function of Interface Modulus 


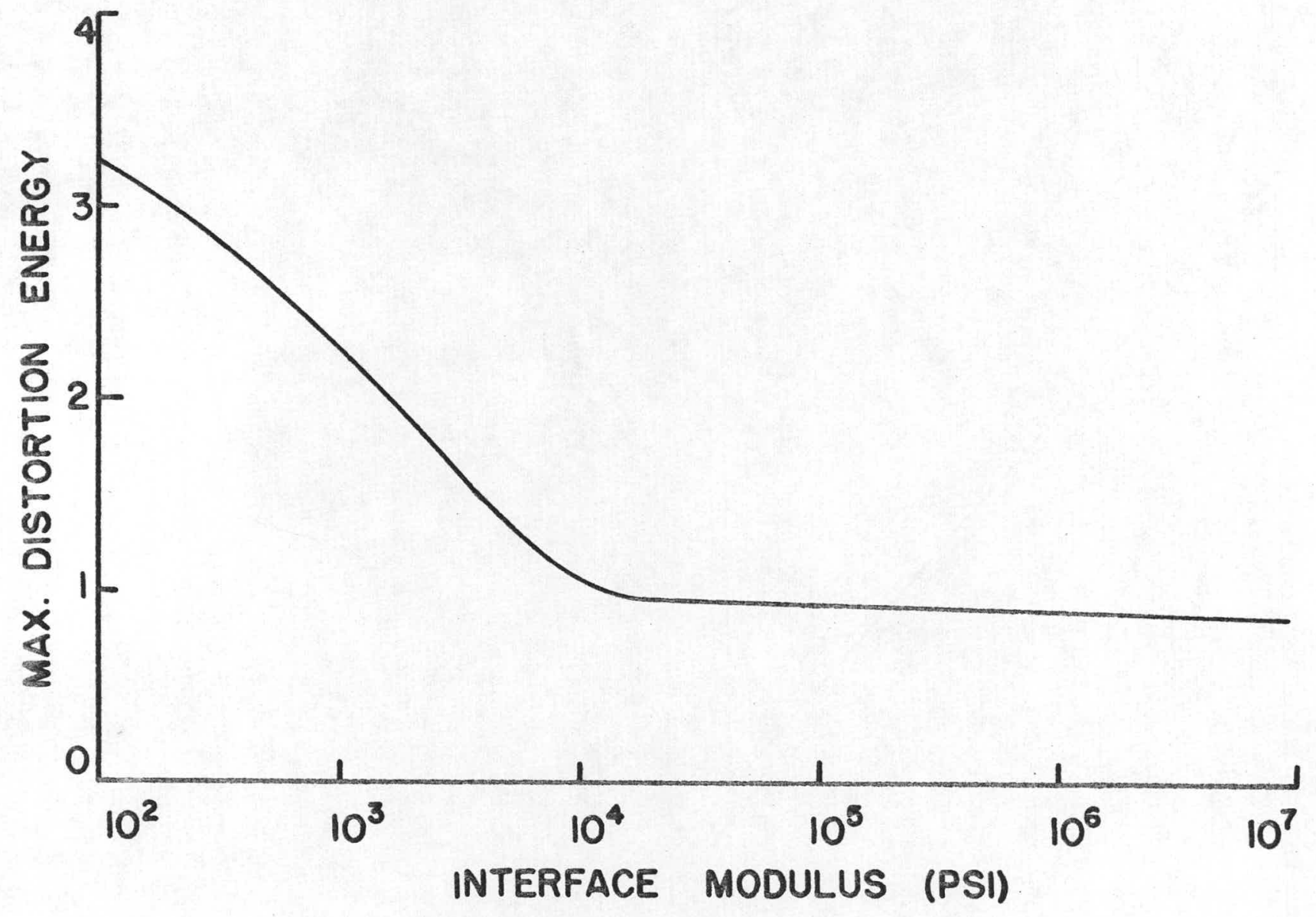

Fig. 15. Maximum Distortion Energy as a Function of Interface Modulus 


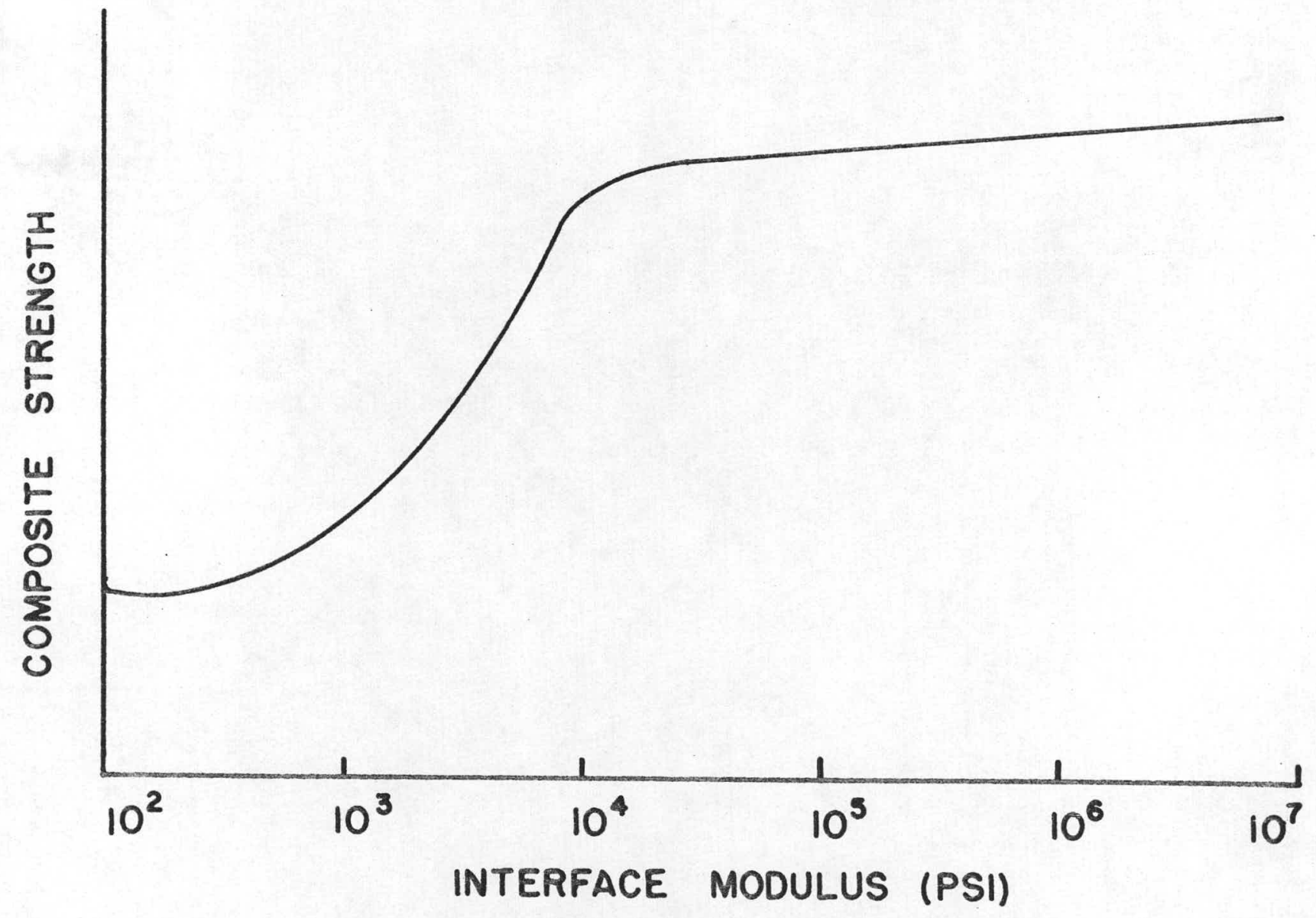

Fig. 16. Composite Strength as a Function of Interface Modulus (Qualitative Representation) 